\title{
Effect of chronic administration of cisapride on gastric emptying of a solid meal and on dyspeptic symptoms in patients with idiopathic gastroparesis
}

\author{
R CORINALDESI, V STANGHELlini, C RAITI, E REA, R SALGEMiNi, \\ AND L BARBARA \\ From the 3rd Medical Clinic, University of Bologna, Italy
}

SUMmARY In a double blind crossover comparison with placebo, the effects of cisapride ( $10 \mathrm{mg}$ tid for two weeks), a non-antidopaminergic gastrointestinal prokinetic drug, on gastric emptying times and on symptoms were evaluated in 12 patients with chronic idiopathic dyspepsia and gastroparesis. Gastric emptying was studied by a radioisotopic gamma camera technique. The test meal was labelled in the solid component (" symptoms (nausea, belching, regurgitations, vomiting, postprandial drowsiness, early satiety, epigastric pain or burning, heartburn) were graded weekly on a questionnaire. Cisapride was significantly more effective than placebo in shortening the $t \frac{1}{2}$ of gastric emptying $\left(p_{2}=0 \cdot() 4\right)$, but no significant difference was observed between the two treatments with regard to the improvement of total symptom score $\left(\mathrm{p}_{2}=0 \cdot 09\right)$. No side effects were reported during the study.

Functional disorders of the gastrointestinal tract are common, and represent the most frequent diagnosis in western gastroenterological practice.'

The syndrome of functional dyspepsia is characterised by non-specific postprandial symptoms in the absence of organic disease. Traditional diagnostic tests often fail to reveal any significant abnormality. Consequently, the pathogenesis is still unclear.

Recent studies using more sophisticated techniques, however, suggest possible gastrointestinal motor abnormalities in some patients. Gastrointestinal manometric studies ${ }^{2}$ and myoelectric recordings ${ }^{34}$ have documented abnormalities in some patients with unexplained dyspeptic symptoms. Delayed gastric emptying of both solids ${ }^{5}$ and liquids have been shown in these patients.

The presence of gastrointestinal motor abnormalities and, specifically, of delayed gastric emptying has formed the basis for use of prokinetic drugs in the treatment of dyspeptic syndromes. Metoclopramide " and domperidone" have been shown to enhance antral contractions, accelerate gastric

Address for correspondence: Prof Roberto Corinaldesi. Clinical Medica $3^{\circ}$. Universita di Bologna. Ospedale Policlinico S. Orsola, Via Massarenti o (40138). Bologna, Itily.

Reccived for publication 27 June I986. emptying and relieve dyspeptic symptoms. Both drugs, to some degree, exert their effects by peripheral dopaminergic receptor blockade. Central dopaminergic receptor blockade with metoclopramide, less so with domperidone, however, can produce side effects. "

Cisapride is a new gastrokinetic drug devoid of antidopaminergic properties." The drug appears to act by directly facilitating acetylcholine release from myenteric plexus, without muscarinic or nicotinic receptor stimulation. "Acute administration of this drug has been shown to accelerate gastric emptying in experimental animals ${ }^{11-13}$ and in man."1t

The aim of the present study was to assess the effect of chronic administration of cisapride on gastric emptying in dyspeptic patients with idiopathic gastroparesis and furthermore to test whether improvement in gastric emptying would correlate with improvement in symptoms.

\section{Methods}

PATIENTS

Twelve consecutive dyspeptic outpatients, five men and seven women, aged between 22 and 52 years (median: 34.5 years) and with body weights ranging 
from 50 to $75 \mathrm{~kg}$ (median: $56.5 \mathrm{~kg}$ ) participated in this study, after having given informed consent. The following criteria had to be met for inclusion in the study: (a) Absence of digestive organic diseases, systemic diseases, previous major abdominal surgery, severe irritable bowel syndrome, important personality disorders and, in women, abnormalities of the menstrual cycle. These were all ruled out by extensive history taking and physical examinations, gastroscopy, ultrasonography, and appropriate biochemical tests. (b) Evidence of delayed gastric emptying. (c) Presence of dyspeptic symptoms with a weekly score $>5$ (see below), for at least one year.

\section{GASTRIC EMPTYING STUDIES}

Gastric emptying was evaluated using a gamma camera radioisotopic technique. The subjects were given a solid liquid meal (caloric value: $568 \mathrm{Kcal}$; composition: $41 \%$ carbohydrate, $21 \%$ protein, $38 \%$ fat). The solid component of the meal consisted of $20 \mathrm{~g}$ fresh chicken liver, $60 \mathrm{~g}$ ground beef, $100 \mathrm{~g}$ potatoes, $10 \mathrm{~g}$ white bread and $160 \mathrm{~g}$ cream caramel. The liquid component consisted of $10 \mathrm{~g}$ olive oil and $200 \mathrm{cc}$ water. The meal was labelled in the solid phase according to a modification of the method proposed by Wright et al ${ }^{15}: 750 \mu \mathrm{Ci}{ }^{{ }^{*} m} \mathrm{Tech}$ etium sulphur colloid ("xim Tc SC) were infiltrated by a tuberculin syringe into the chicken liver. The liver was then cooked to a firm consistency, separated from any juices produced during cooking, finely diced, mixed with the ground meat and cooked again, to form a hamburger. The validity of this labelling procedure was tested in vitro, as described below.

The meal was consumed at $1 \mathrm{pm}$, after at least a five hour fast. No attempt to control the rate or extent of mastication was made. Immediately after eating the meal, the patients laid supine under the $140 \mathrm{Kev}$ diverging multihole collimator head of a gamma camera (PHO/gamma IV Searle, Nuclear Chicago), with the head $30^{\circ}$ elevated.

Imaging started immediately after ingestion of the meal $($ time $=0)$. Data were collected continuously for 120) minutes, summed at one minute intervals and stored on discs for later analysis.

On completion of the emptying study, the stored data were processed by a digital computer (Digital PDP 11/34). A video monitor permitted selection of an area of interest, representing the isotope contained in the stomach. The counts occurring within this area were obtained for each of the 120 frames collected. Decay factors were used to compensate for the decline in radioactivity of ${ }^{4 m_{m}} \mathrm{Tc}$.

The gastric emptying curves were plotted as percentage of isotope still present in the stomach against time. These curves were then fitted using a power exponential function ${ }^{16}$ and results were calculated using a BASIC program on a separate computer (M20-Olivetti-Italy) and expressed as $t^{1} \frac{1}{2}$.

The non-linear least-square computer program used to obtain the fitted power exponential curves also provides a measure of goodness of fit, expressed as $\mathrm{R}^{2}$ (1-residual sum of squares/total sum of squares).

Gastric emptying was evaluated by this method in 15 healthy volunteers without a history of digestive disorders: 12 men and three women, aged $32 \cdot 3 \pm 8 \cdot 7$ years $(\mathrm{M} \pm \mathrm{SD})$ and weighing $66 \cdot 2 \pm 1() \cdot 7 \mathrm{~kg}$. The $95 \%$ confidence interval ( $70-125 \mathrm{~min})$ served to determine the presence of gastric stasis in the dyspeptic patients we examined. Only patients with gastric emptying $t 1 / 2$ longer than $125 \mathrm{~min}$ were included in the present study.

\section{DYSPEPTIC SYMPTOMS SCORING}

Each patient was instructed to complete weekly a questionnaire listing nine symptoms: nausea, belching, regurgitations, vomiting, postprandial headache, postprandial drowsiness, early satiety, epigastric pain or burning, heartburn. Each symptom was graded, on a weekly basis: $0=$ absent; $1=$ occasionally, slight; $2=$ moderately often, moderately severe; $3=$ very often, markedly severe. Two hundred and eighteen healthy volunteers, 130 men and 88 women, aged $41 \cdot 1 \pm 1() \cdot 3$ years $(\mathrm{M} \pm \mathrm{SD})$, had previously completed this questionnaire and served as controls. In this group we obtained weekly scores ranging from 0 to 5 , which were considered normal values. A total weekly symptom score greater than 5 was therefore required for entry into the study.

\section{EXPERIMENTAI. DESIGN}

All patients considered eligible for the study on the basis of symptoms were included. All medication was withdrawn and patients entered into a one week drug free run in phase. At the end of this week, gastric emptying was measured. Only patients with delayed gastric emptying were admitted to the trial.

The patients were then randomised and treated with cisapride $10 \mathrm{mg}$ tid orally, 15 minutes before the meal, and matching placebo, each given for two weeks, under double blind conditions. Six patients received cisapride first ( $\mathrm{CP}$ group), six placebo ( $\mathrm{PC}$ group). At the end of each treatment period, gastric emptying tests were carried out. In order to evaluate gastric emptying in steady-state conditions of the test drugs, the last tablet of each treatment was administered 15 minutes before ingestion of the labelled meals.

STATISTICAL ANALYSIS

Non-parametric statistical tests were used and 2-tailed $p$ values were computed. 


\section{(a) Comparability of treatment groups}

The pretreatment comparability of the PC and CP groups was evaluated by means of the Fisher exact test (for sex) and the Mann-Whitney U-test (other variables).

\section{(b) Crossover analysis}

Intermedication differences of changes in $t^{1} / 2$ values and changes in symptom scores were evaluated by means of the Mann-Whitney U-test in an analysis for the two period crossover design. ${ }^{17}$ This analysis discriminates between treatment effects, period effects, and residual effects. As an interperiod washout was impracticable and, in order to minimise any possible carryover effects, only the symptom scores of the second week of each period was taken into account for statistical analysis.

\section{(c) Intraindividual changes of $t^{1 / 2}$ and total symptom} score

As no significant residual or period effects occurred regarding either $t^{1 / 2}$ values or the total symptom score, as evidenced by application of the two period crossover analysis, results of both sequence groups were merged according to the treatment (cisapride period $1+2$, placebo period $1+2$ ). Intraindividual changes (post- pretreatment) were calculated and evaluated using Wilcoxon's matched-pairs signedranks test.

(d) Correlation of the changes in total symptom score and the changes in gastric emptying rate of solids Changes in gastric emptying times after two weeks of treatment relative to the condition at selection, were expressed as:

$$
\frac{t^{1 / 2}(\text { basal })-t^{1 / 2}(\text { drug })}{t^{1 / 2}(\text { basal })+t^{1 / 2}(\text { drug })} \times 200
$$

and compared with the corresponding changes in the total symptom complex (Spearman rank correlation coefficient $r_{s}, 2$-tailed probability).

\section{IN VITRO STUDIES}

To evaluate the stability of 'in vitro' labelled chicken liver, $0.5 \mathrm{~g}$ portions of finely diced cooked labelled liver were agitated at $37^{\circ} \mathrm{C}$ in tubes containing $2 \mathrm{ml}$ filtrated fresh gastric juice. Solid particles and supernatant were separated by centrifugation at $540 \mathrm{~g}$ for 15 minutes and then counted by a scintillator well counter (gamma-counter AMSR, Abbott, USA). After a 90 minute incubation, $98 \pm 2 \%(M+S D$; nine samples) of radioactivity was still bound to the solid. An identical technique was used to validate the stability of other radiolabelled solid foods commonly used in gastric emptying studies. When 'in vivo' "
Table 1 Mean and median $1 / 2$ values ( $\min$ ) before and at the end of 2 weeks of treatment with cisapride or placebo

\begin{tabular}{llll}
\hline & Basal & Cisapride & Placebo \\
\hline Mean & $285 \cdot 1$ & $143 \cdot 6$ & $264 \cdot 3$ \\
SD & $181 \cdot 63$ & $58 \cdot 53$ & $146 \cdot 87$ \\
Median & $209 \cdot 5$ & $118 \cdot 0$ & $238 \cdot()$ \\
Extremes & $(131-652)$ & $(68-250)$ & $(113-578)$ \\
\hline & & & \\
\cline { 2 - 3 } & & &
\end{tabular}

SC labelled chicken liver ${ }^{18}$ was tested, similar results were obtained, $97 \pm 8 \%$ of the radioactivity still being found in the solid. In contrast, after incubation of ${ }^{51} \mathrm{CrCl}_{3}$ ground beef meat ${ }^{14}$ and ${ }^{49 m} \mathrm{Tc}$ SC egg white, ${ }^{211}$ leakage of the isotopes was significantly greater; the percentages of radioactivity still bound to the solid after 90 minutes were respectively $81 \pm 8 \%(\mathrm{p}<0.01)$ and $69 \pm 5 \%(p<0 \cdot 01$, by Wilcoxon's rank sum test). These results are similar to those obtained by 'in vivo' validation techniques carried out using intubation in healthy volunteers. ${ }^{1921}$ 'In vitro' "\%m Tc SC labelled chicken liver has a stability similar to 'in vivo' labelled liver which requires a particularly cumbersome preparation. Furthermore, it appeared more reliable than ${ }^{51} \mathrm{CrCl}_{3}$ ground meat and ${ }^{4 \% m} \mathrm{Tc} \mathrm{SC}$ egg white. For these reasons, all studies in man reported in this study were carried out using chicken liver, 'in vitro' labelled with ${ }^{44 \mathrm{~m}} \mathrm{Tc}$ SC.

\section{Results}

All the patients completed the trial without reporting any side effects attributable to the treatment.

Except for the symptom 'regurgitation' which was significantly more prominent in the cisapride group than in the placebo group, the two groups were comparable at the start of the study as to be age and sex distribution, severity of dyspeptic symptoms and $t^{1} / 2$.

\section{RESPONSE OF GASTRIC EMPTYING}

Gastric emptying curves of the solid component of the test meal were satisfactorily fitted by the power exponential analysis $\left(R^{2}\right.$ : median $=0.96$; range: $0 \cdot 77$ $0.99)$.

Table 1 gives the mean $( \pm \mathrm{SD})$ and median values of $t^{1 / 2}$. The global curves based on median values of individual fitted curves are displayed in Figure 1.

Cisapride caused a significant acceleration of gastric emptying, the mean $t^{1 / 2}$ being halved, when compared with the basal values (means: $143.6 \mathrm{vs}$ 285.1 min; medians: 118.0 vs 209.5 min; $P_{2}=0.012$ ). Two patients, however, had little or no improvement, whereas one emptied solids even slower than 


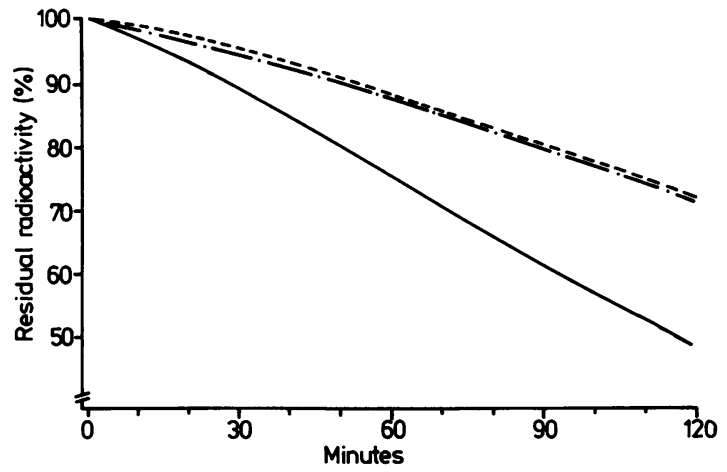

Fig. 1 Gastric emptying curves in basal conditions (-- - ) and at the end of a two-week treatment with cisapride (-) or placebo (-.-- - ). Each curve represents the median $(n=12)$ of $\%$ of ingested marker within the stomach versus time.

before the treatment. Placebo treatment resulted in a slight deterioration in one, severe deterioration in two, slight improvement in six and no change in three patients. Gastric emptying times after placebo treatment were not statistically different from the pretreatment values (means: 264.3 vs $285.1 \mathrm{~min}$; medians: $238.0 v s 209.5 \mathrm{~min} ; \mathrm{p}_{2}=0.52$ ).

The difference between cisapride and placebo in improving the patients' stomach evacuation rate was significant $\left(\mathrm{p}_{2}=0 \cdot 042\right)$.

\section{RESPONSE OF SYMPTOMS}

The effects of cisapride and placebo on the mean and median values of the weekly scores are shown in Table 2. Table 3 shows the effects of treatments on the discrete symptoms in both sequence groups. In comparison with the situation at the start, both cisapride and placebo significantly improved the total symptom scores $\left(p_{2}=0.002 ; p_{2}=0.012\right.$, respectively), but no significant difference $\left(\mathrm{p}_{2}=0 \cdot 09\right)$ was detected between the two treatments.
Table 2 Mean and median symptoms scores in the pretrial period and during the second week of treatment with cisapride or placebo

\begin{tabular}{llll}
\hline & Basal & Cisapride & Placebo \\
\hline Mcan & $10 \cdot 2$ & $6 \cdot 1$ & $7 \cdot 3$ \\
SD & $3 \cdot 33$ & $4 \cdot 64$ & $4 \cdot(33$ \\
Median & $9 \cdot 0$ & $4 \cdot 5$ & $6 \cdot 5$ \\
Extremes & $(6-16)$ & $(1-15)$ & $(2-16)$ \\
\hline & & & \\
\cline { 2 - 4 } & &
\end{tabular}

\section{CLINICAL IMPROVEMENT VERSUS ACCELERATION} OF GASTRIC EMPTYING

Compared with pretreatment levels, two weeks' treatment with cisapride resulted in improvement of the clinical symptoms, as well as in a significant shortening of gastric emptying rate times. As depicted in Figure 2, the relative changes in symptom scores correlated significantly with the relative changes in gastric emptying rates $\left(r_{s}=0.69 ; p_{2}<0.025\right)$. No such correlation was seen after placebo treatment $\left(r_{s}=0 \cdot 12 ; \quad p_{2}=0 \cdot 72\right) ; \quad$ although symptoms also improved, compared with the pretreatment conditions, gastric emptying rates changed little during placebo treatment.

\section{Discussion}

The term dyspepsia includes a wide range of digestive disorders from the mild disturbance experienced by most healthy individuals after eating over large over rich meals to very severe conditions with gross abnormalities of gastrointestinal motility such as in chronic intestinal pseudo-obstruction. To consider dyspeptic patients as a whole may, therefore, be misleading, especially when the effect of a therapy is tested.

In the present study, an attempt has been made to

Table 3 Effects of treatments on the discrete symptoms $(M \pm S D)$ in both sequence groups

\begin{tabular}{|c|c|c|c|c|c|c|}
\hline & \multicolumn{3}{|l|}{ C-P group } & \multicolumn{3}{|l|}{ P.Cgroup } \\
\hline & Basal & Cisapride & Placebo & Basal & Placebo & Cisapride \\
\hline Early saticty & $2 \cdot 2 \pm 0 \cdot 40(6)$ & $1 \cdot 3 \pm 0 \cdot 51(6)$ & $1.7 \pm 0.81(6)$ & $1.8 \pm 0.75(6)$ & $1 \cdot 0 \pm 0.63(5)$ & $0.5 \pm 0.54(3)$ \\
\hline Belching & $1 \cdot 7 \pm 0.52(6)$ & $1 \cdot 3 \pm 0 \cdot 52(6)$ & $1.2 \pm 0.41(6)$ & $1.8 \pm 0.41(6)$ & $1.3 \pm 0.82(5)$ & $1 \cdot 0 \pm 0 \cdot 63(5)$ \\
\hline Epigastric pain & $2 \cdot 0 \pm 1 \cdot 26(5)$ & $1 \cdot 5 \pm 1 \cdot 22(4)$ & $1 \cdot 5 \pm 1 \cdot 04(5)$ & $1 \cdot 3 \pm 1 \cdot 50(3)$ & $0.7 \pm 0.81(3)$ & $0.5 \pm 0.54(3)$ \\
\hline Drowsiness & $1 \cdot 7 \pm 0 \cdot 51(6)$ & $1 \cdot 2 \pm 0.98(4)$ & $1.8 \pm 0.75(6)$ & $1.7 \pm 1.21(5)$ & $1 \cdot 0 \pm 1.26(3)$ & $0.8 \pm 0.98(3)$ \\
\hline Regurgitations & $1 \cdot 7 \pm 0 \cdot 81(6)$ & $1 \cdot 8 \pm 1 \cdot 16(5)$ & $0 \cdot 8 \pm 0.98(3)$ & $0.3 \pm 0.51(2)$ & $0.5 \pm 0.54(3)$ & 0.0 \\
\hline Nausea & $1 \cdot 0 \pm 1 \cdot 54(2)$ & $1.0 \pm 1.54(2)$ & $1.0 \pm 1.26(3)$ & $0.8 \pm 0.75(4)$ & 0.0 & $0 \cdot(0)$ \\
\hline Vomiting & $0 \cdot 7 \pm 1.03(2)$ & $0 \cdot 7 \pm 1.03(2)$ & $0 \cdot 7 \pm 1 \cdot 03(2)$ & $0.2 \pm 0.40(1)$ & $0 \cdot 0$ & $0 \cdot()$ \\
\hline Headache & $0.0 \quad(0)$ & $0 \cdot 2 \pm 0 \cdot 40(1)$ & $0.3 \pm 0.51(2)$ & $0 \cdot 8 \pm 1.32(2)$ & $0 \cdot 8 \pm 1 \cdot 32(2)$ & $(0 \cdot 2 \pm 0 \cdot 40(1)$ \\
\hline Heartburn & $0 \cdot 0$ & $0 \cdot 0$ & $0.2 \pm 0.40(1)$ & $0.5 \pm 0.83(2)$ & $0.2 \pm 0.40(1)$ & $0 \cdot 2 \pm 0.40(1)$ \\
\hline Total & $10 \cdot 8 \pm 3 \cdot 54$ & $9 \cdot 0 \pm 4.85$ & $9 \cdot 2 \pm 4 \cdot 35$ & $9 \cdot 5 \pm 3 \cdot 27$ & $5 \cdot 5 \pm 2 \cdot 94$ & $3 \cdot 2 \pm 1 \cdot 83$ \\
\hline
\end{tabular}

(n) = number of patients presenting the symptom. 


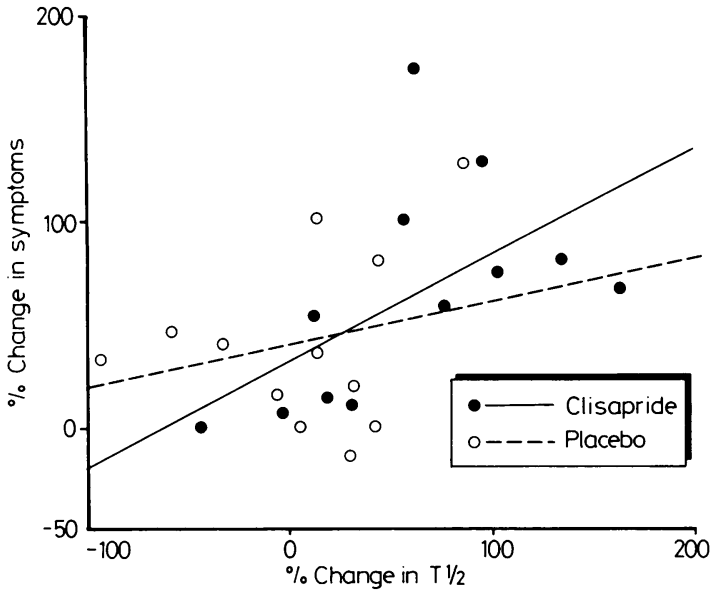

Fig. 2 Correlation between relative (vs basal) changes in symptom scores and gastric emptying $t 1 / 2$ after 2 -week treatment with cisapride and placebo.

define a group of patients as homogenous as possible. Specifically, patients with secondary dyspepsia were excluded. Neither were included patients with mild, infrequent or short lived symptoms in order to minimise the chances of clinical improvements because of spontaneous fluctuations of the disease, rather than to the actual effects of the therapy. To further select a specific category of dyspeptic patients and to show objectively responses to the treatments, only subjects with symptoms associated with a proven delay of gastric emptying were included. Abnormal gastric emptying is not necessarily caused by a gastric disorder, however, recent studies showed that delay of gastric emptying ${ }^{22}$ and inhibition of postprandial antral motility ${ }^{3:}$ can be induced by centrally acting stressful stimuli in healthy individuals, via endocrine ${ }^{2 t}$ and, probably, nervous ${ }^{25}$ pathways. Therefore, in our study, psychiatric disorders, such as depression ${ }^{2 n}$ and anorexia nervosa, ${ }^{-7}$ were excluded and efforts were made to ascertain that anxiety did not play a major role in the pathogenesis of digestive symptoms in our patients.

In 12 such carefully selected patients, cisapride produced a significant acceleration of gastric emptying of solids, compared with placebo. On the contrary, no significant difference was found between the two treatments regarding to the effects on symptoms. Both drugs induced a symptomatic improvement, compared with the pretreatment values. The symptomatic effect produced by placebo is a well recognised phenomenon in upper gastrointestinal disorders. ${ }^{2 *}$ Cisapride might have induced a similar symptomatic improvement, compared with pretrial conditions, by a placebo effect. Statistical analysis, however, showed a significant correlation between symptomatic improvements and increased rates of gastric emptying induced by cisapride, with respect to the pretrial conditions. This raises once again the all important question, if any exists, between digestive symptoms and objective identification of gastrointestinal motor abnormalities.

In a recent study on patients with irritable bowel syndrome, symptoms were reported to occur invariably concomitant to recognisable episodes of irregular interdigestive motility of the small bowel." This does not seem to be the case in functional dyspepsia, as extensive evaluation often fails to reveal motility disorders in such patients.

In the present study, we excluded patients who had been referred to us complaining of dyspeptic symptoms, in whom gastric emptying times turned out to be normal. These approximately represent $50 \%$ of the patients with unexplained dyspepsia." Other studies showed that, although the vast majority of patients with severe dyspepsia present manometric abnormalities during either fasting, or fed, or both, in approximately $20 \%$ of them no recognisable motility disorder can be detected; also, no symptomatic difference was observed between these patients with normal motility and those with gastric dysmotility, or gastric plus intestinal dysmotility.'

A relationship between gut motor abnormalities and dyspeptic symptoms is, therefore, far from being established. Gastrointestinal motor abnormalities, such as gastroparesis, may or may not represent the cause of dyspeptic symptoms.

Functional dyspepsia is a heterogenous syndrome and new diagnostic methodologies are being needed to clarify the different pathogenetic mechanisms of dyspeptic symptoms and, consequently, to indicate more specific therapeutic approaches.

We wish to thank Janssen Pharmaceutica for the supply of cisapride. This paper was presented in part at the 2nd European Symposium on Gastrointestinal Motility, Oxford, September 5-7, 1984.

\section{References}

1 Switz DM. What the gastroenterologist does all day. A survey of a state society' practice. Gastroenterology 1976; 70: $1048-50$.

2 Malagelada JR, Stanghellini V. Manometric evaluation of functional upper gut disorders. Gastroenterology 1985; 88: $1223-31$.

3 Telander RL, Morgan KG, Kreulen DL. Schmalz PF, Kelly KA, Szurszewski JH. Human gastric atony with tachygastria and gastric retention. Gastroenterology 1978; 75: 497-501.

4 You CH. Lee KJ, Chey WY, Menguy R. Electrogastrographic study of patients with unexplained nausea, bloating and vomiting. Gastroenterology 1980; 79: $311-4$. 
5 Rees WDW, Miller LJ, Malagelada JR. Dyspepsia antral motor dysfunction and gastric stasis of solids. Gastroenterology 1980; 78: 360)-5.

6 Jian R, Ducrot F, Piedeloup C, Mary JY, Najean Y, Bernier JJ. Measurement of gastric emptying in dyspeptic patients. Effect of a new gastrokinetic agent (cisapride). Gut 1985; 26: 352-8.

7 Schulze-Delrieu K. Metoclopramide. Gastroenterology 1979; 77: 768-79.

8 Schulze-Delricu K. Metoclopramide. $N$ Engl J Med 1981; 305: 28-33.

9 Brogden RN, Carmine AA, Heel RC, Speight TM, Avery GS. Domperidone. A review of its pharmacological activity, pharmacokinetics and therapeutic efficacy in the symptomatic treatment of chronic dyspepsia and as antiemetic. Drugs 1982;24: 360)-400.

10 Reyntjens A, Verlinden M, Schuurkes JAJ, Van Neuton J, Janssen PAJ. New approach to gastrointestinal motor dysfunction: non-antidopaminergic, non-cholinergic stimulation with cisapride. Curr Ther Res 1984; 36: 1029-37.

11 Pfeuffer-Friederich I, Kilbinger $H$. Facilitation and inhibition by 5-hydroxytryptamine and R 51619 of acetylcholine release from guinea pig myenteric neurones. In: Roman C, ed. Gastrointestinal motility, Lancaster: MTP Press, 1984: 527-34.

12 Schuurkes JAJ, Van Neuten JM, Van Daele PGH, Reyntjens AJ, Janssen PAJ. Motor stimulating properties of cisapride on isolated gastrointestinal preparations of the guinea pig. J Pharmacol Exp Ther (in press).

13 Suzuki T, Nakaya M, Arai H, Wakabayashi K, Itoh Z. Characteristic motor stimulating effect of cisapride on gastrointestinal tract in conscious dogs. [Abstract]. Gastroenterology 1984; 86: 1271.

14 Corazziari E, Scopinaro F, Bontempo I, et al. Effect of R 51619 on distal oesophageal motor activity and gastric emptying. [Abstract]. Ital J Gastroenterol 1983; 15: 185-6.

15 Wright RA, Thompson D, Syed I. Simultaneous markers for fluid and solid gastric emptying: new variations on an old theme: concise communication. J Nucl Med 1981; 22: 772-6.

16 Elashoff JD, Reedy TJ, Meyer JH. Analysis of gastric emptying data. Gastroenterology 1982; 83: 1306-12.
17 Koch GG. The use of non-parametric methods in the statistical analysis of the two period change-over design. Biometrics 1972; 28: 577-84.

18 Meyer JH, Mac Gregor IL, Gueller R, Martin P, Cavalieri R. $99 \mathrm{mTc}$-tagged chicken liver as a marker of solid food in the human stomach. Dig Dis 1976; 21: 296-304.

19 Malagelada JR. Quantification of gastric solid-liquid discrimination during digestion of ordinary meals. Gastroenterology 1977; 72: 1264-7.

20 Kroop HS, Long WB, Alavi A, Hansell JR. Effect of water and fat on gastric emptying of solid meals. Gastroenterology 1979; 77: 997-10)0.

21 Jobin G, Jian R. Isotope studies in gastric emptying. Dig Dis Sci 1982; 27: 571-2.

22 Thompson DG, Richelson E, Malagelada JR. Perturbation of upper gastrointestinal function by cold stress. Gut 1983; 24: 277-83.

23 Stanghellini V, Malagelada JR, Zinssmeister AR, Go VLW, Kao PC. Stress-induced gastroduodenal motor disturbances in humans: possible humoral mechanisms. Gastroenterology 1983; 85: 83-91.

24 Stanghellini V. Malagelada JR, Zinsmeister AR, Go VLW, Kao PC. Effect of opiate and adrenergic blockers on the gut motor response to centrally acting stimuli. Gastroenterology 1984; 87: 1104-13.

25 Stanghellini V, Corinaldesi R, Tovoli S, et al. Effects of acute stress on vagally stimulated gastric acid secretion and pancreatic polypeptide (PPH) levels in man. [Abstract]. Gastroenterology 1985; 88: 1597.

26 Haggerty JJJ, Golden RN. Psychogenic vomiting associated with depression. Psychosom Med 1982; 23: 91-5.

27 Dubois A, Gross HA, Ebert MH. Castell DO. Altered gastric emptying and secretion in primary anorexia nervosa. Gastroenterology 1979; 77: 319-23.

28 Shapiro AK. A contribution to a history of the placebo effect. Behav Sci 1960; 5: 109-35.

29 Kumar D. Wingate DL. The irritable bowel syndrome: a paroxysmal motor disorder. Lancet 1985; 2: 926-30.

30 Corinaldesi R, Stanghellini V, Raiti C, et al. Gastric acid secretion and gastric emptying of solids in patients with chronic idiopathic dyspepsia. [Abstract]. In: Proceedings 8th World Congress of Gastroenterology, Sao Paolo-September 1986 (in press). 